\title{
A new invention to transfer the patients from ordinary hospital beds to surgical beds and vice versa in two states of railing and transferring, a pictorial review
}

\begin{abstract}
The process of transferring the patients from ordinary hospital beds to surgical beds and vice versa is really a long lasting challenge in medicine and surgery. Every health care center which deals with transferring the patients from one bed to another may be encountering with this major problem. This problem will be most pronounced when we would like to talk about the surgical and neurosurgical patients specifically with various degrees of cord injuries and multiple trauma, burned patients, orthopedic patients with disability and inability in movement, patients suffering from cancer and with various degrees of weakness and disabilities and older patients with various degrees of paralysis and movement disorders. Many patients with various degrees of Spinal cord injury need close care because a very small change in the alignment of the fixed spinal cord can cause a very dangerous consequence for them. Also the patients with various degrees of disabilities by any congenital or acquired movement disorders or the patients who are suffering from any fractures specifically in their big bones and joints, during the process of transferring may encounter other problems which can have so many dangerous consequences for them. So finding a way to give an answer to this important question that "How can we transfer the patients from one bed to another without causing any problem for them?" was the foundation of designing and manufacturing a device that can facilitate this difficult process.
\end{abstract}

Volume I Issue 4 - 2014

\section{Behzad Saberi, Behrouz Damirloojamaat Iranian Medical Council, Iran}

Correspondence: Behzad Saberi, Member of the Iranian Medical Council no 24, Shahed South Molasadra Street, Esfahan, Iran,Tel (00)98-(0)9|3।263487, Email sab64b@yahoo.com

Received: October 19, 2014 | Published: December 17, 2014

Keywords: New Invention, Transferring patients with a mechanical instrument, Patients safety, Surgical and Neurosurgical patients, Patients with cancer and disabilities

\section{Invention}

In this pictorial review we would like to introduce a new invention in the form of a new device that can solve this important problem of transferring the patients. We could build a device which can transfer the patients from ordinary hospital beds to surgical beds and vice versa in a very safe manner without causing any problem or danger to the patients. In Figure 1, the device can be seen as a whole. Grossly, the device contains some major parts from bottom to top include wheels, Main structure and Engine with some appendices. ${ }^{1-4}$ In Figure 2 , the device can be seen from another angle with a closer look. As it can be seen in this picture, the device has a chassis on one side. When the chassis is being pushed down, a part of the device- which is responsible for elevating the patient from the bed- will come down to its lowest position (Figure 3). After coming to the lowest possible position (which it is directly depends on the basic height of the patient's bed), the clamps will be attached and closed. After pushing up the chassis, this part of the device will go up and this time the patient will be elevated to the highest point (Figure 4). So the alignment of the spinal cord will not be changed during this movement and the patient can be transfer without human force and with ease. After lifting the patient to the highest point, the patient can be transferred to another bed with wheels and then will be put on the other bed with the same mechanism. The important point regarding this method of transferring is that during the whole process of transferring, the patient is lying in a comfortable position and there would be no external force to apply during the process that may cause any damage to the patient.

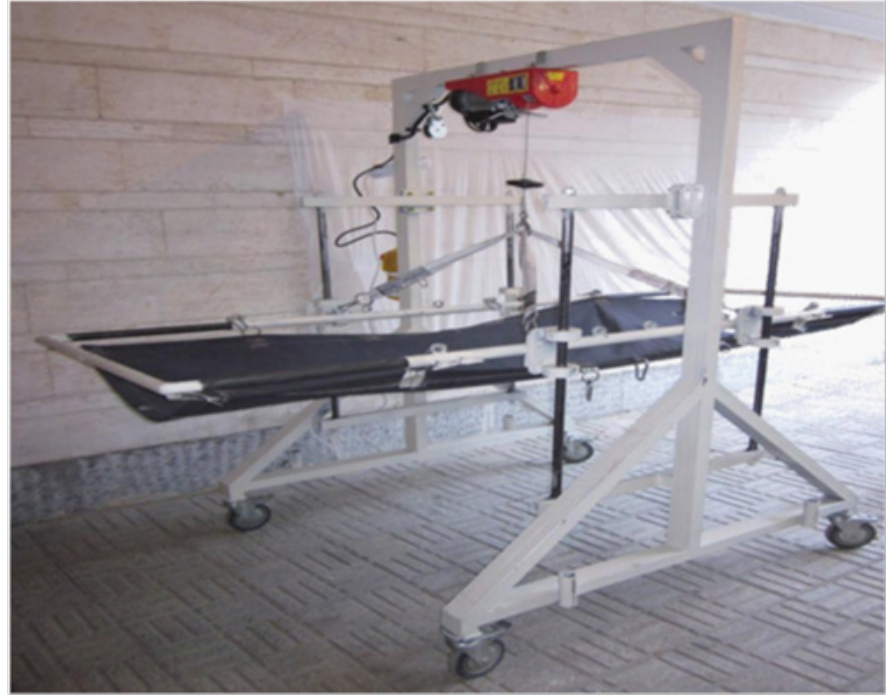

Figure I The device as a whole.

In (Figure 5), The Engine of the device can be seen. In (Figure 6), the lower part of the device contains the wheels can be seen. In (Figure 7), the part of the device which the patient will be transferred by that is shown from above. In (Figure 8), the Chassis of the device can be seen. 


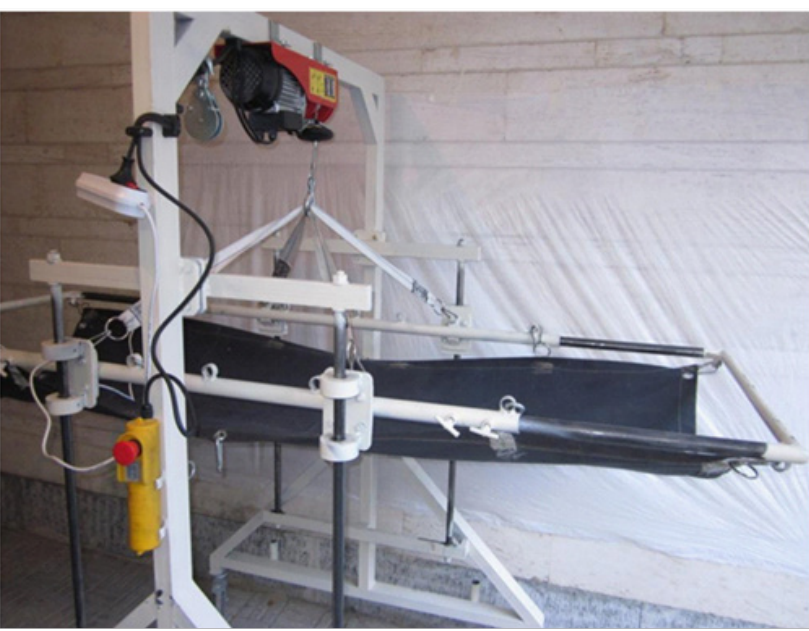

Figure 2 The device from another angle - a closer look.

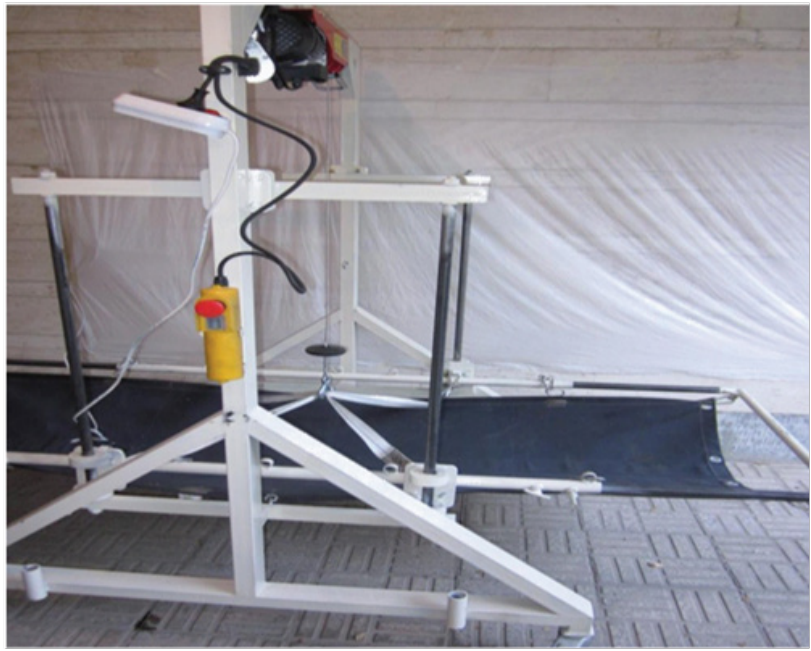

Figure 3 The part of the device which will elevate the patient is in its "lowest" position.

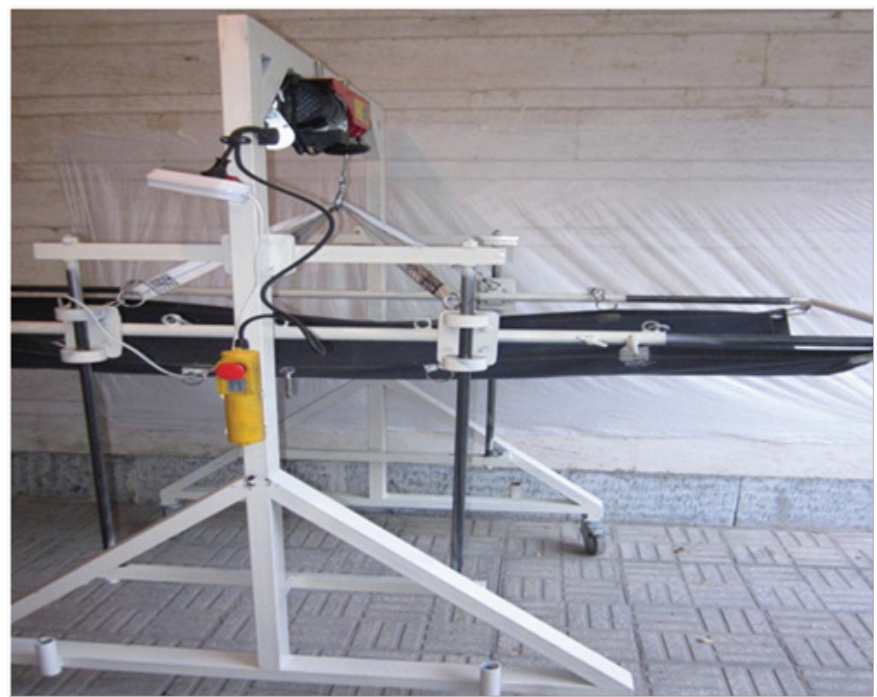

Figure 4 The part of the device which will elevate the patient is now in its "highest" position.

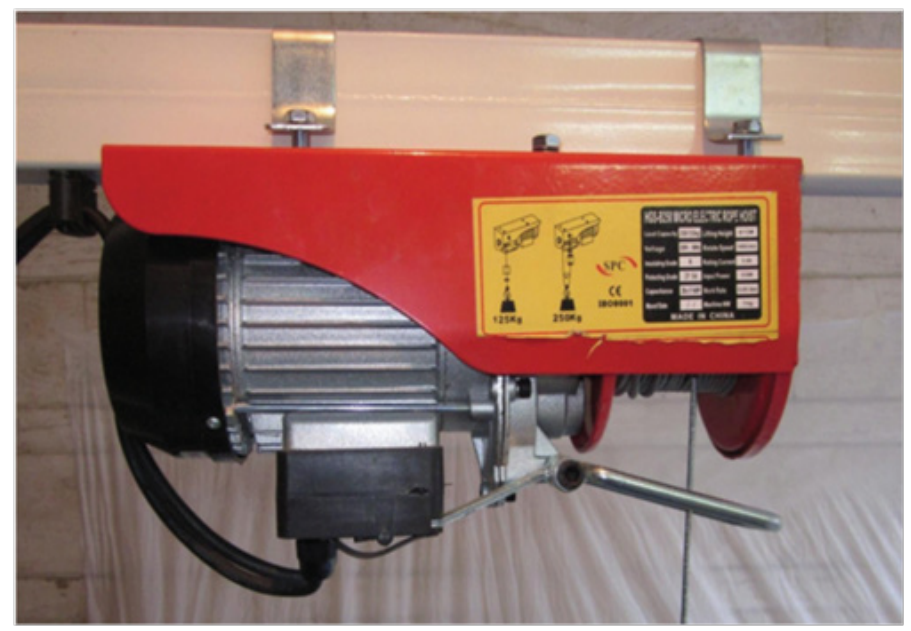

Figure 5 The Engine.

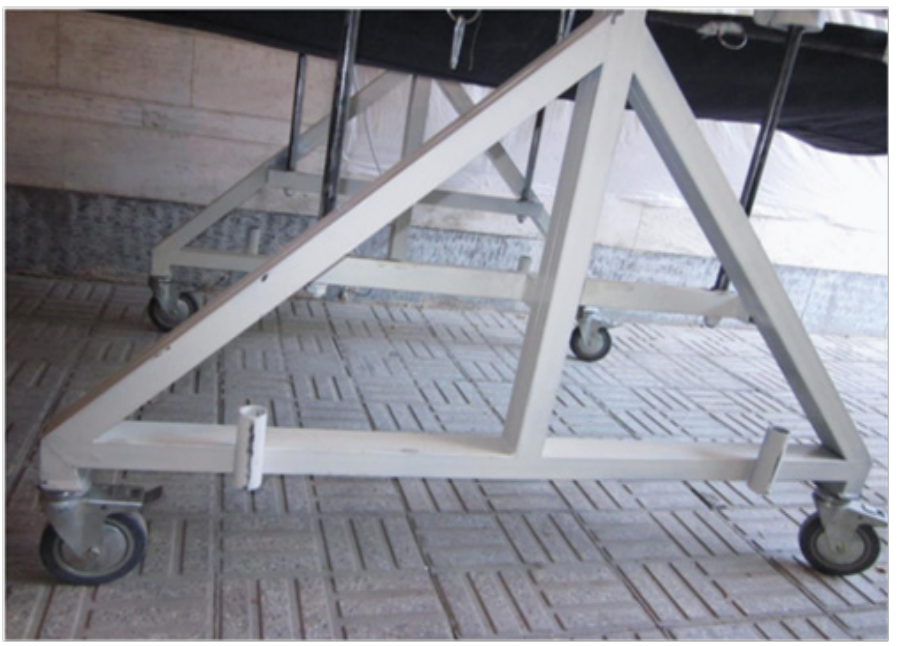

Figure 6 The lower part of the device.

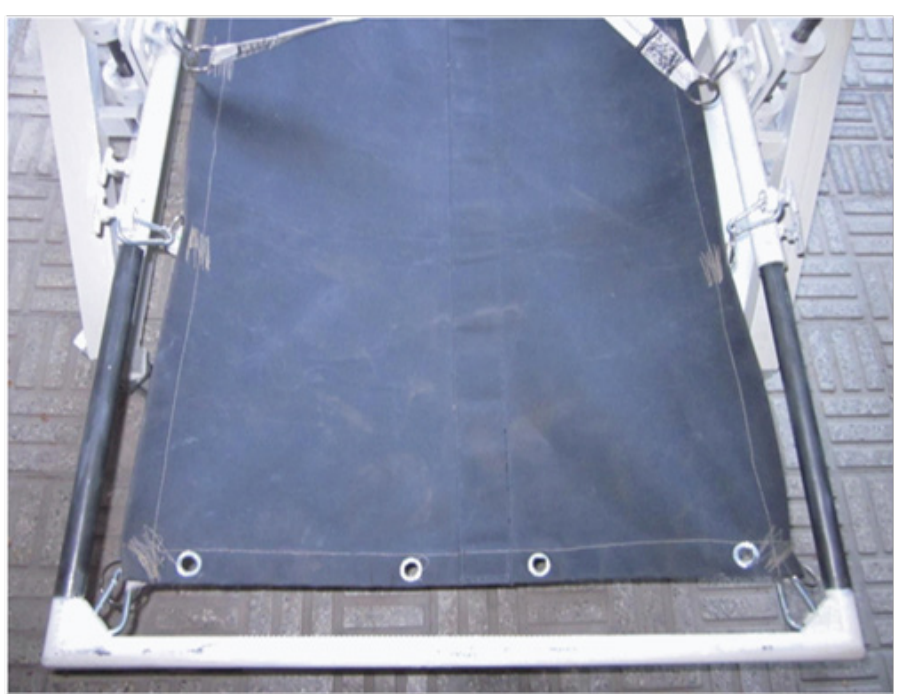

Figure 7 The part of the device which the patient will be lying on it during transferring. 


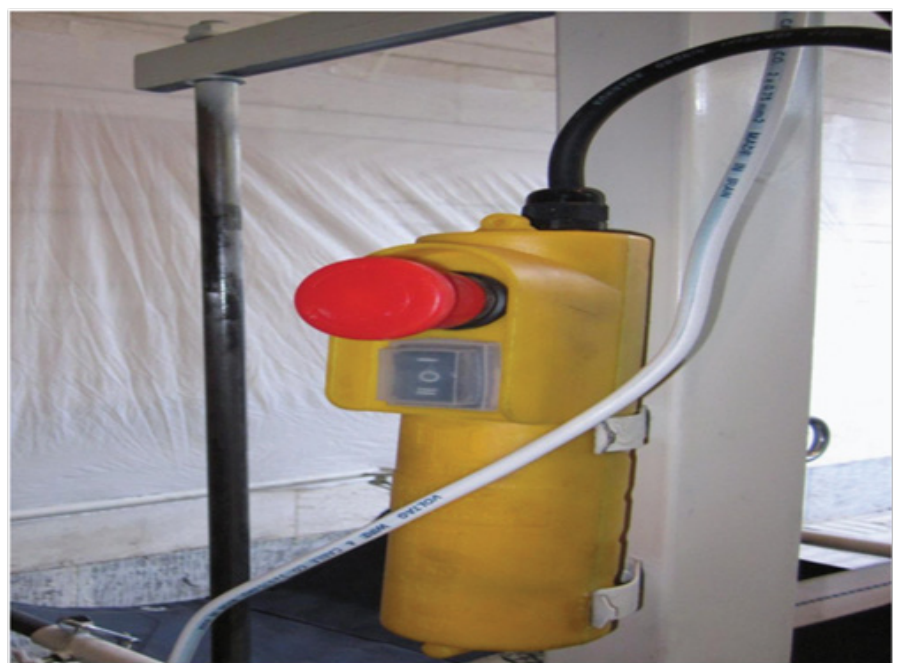

Figure 8 The Chassis.

\section{Discussion}

In summary, to mention the major advantages of this invention we can point to these notes:

i. There is no need to use direct human force to transfer the patients, so the important part of the process of transferring the patients will be done very easily and safely and the patient will encounter no problem or damage during the process ii. The whole process of moving the patients can be under the control, so there would be no sudden unexpected movement of the patients

iii. There would be no risk of any damage to the patients during transferring

iv. The patients with various problems such as immobility, spinal cord injury, various degrees of paralysis and movement disorders, older patients with disability, patients with multiple trauma and fractures, burned patients, patients suffering from cancer and have various degrees of weakness and so on can take advantage of this invention in addition to the routine patients.

\section{Conclusion}

This was a summary of explanation of a new invention in medicine and surgery. We really believe that this invention can solve so many problems of the patients and various patients can take advantage of this new device.

\section{References}

1. Nancy marie phillips. Berry and kohn's operating room technique $\left(12^{\text {th }}\right.$ edn), Elsevier, USA, 2013;pp. 1056.

2. Rothrock Jane C. Alexander's care of the patient in surgery $\left(14^{\text {th }}\right.$ edn $)$, Elsevier, Mexico, USA, 2010;pp. 1328.

3. Joanna Kotcher Fuller. Surgical Technology: Principles and Practice (6 $6^{\text {th }}$ edn), Elsevier, USA, 2013;pp. 1136.

4. Brunicardi FC, Dana K, Andersen, et al. Schwartz's Principles of Surgery. ( $9^{\text {th }}$ edn), McGraw-Hill, 2010. 